\title{
Cẹmetáa
}

\section{Colecionismo bibliográfico: contexto histórico, terminologia e perspectivas de estudo na Ciência da Informação}

\author{
Admeire da Silva Santos Sundström \\ Doutoranda; Universidade Estadual Paulista, Marília, SP, Brasil ; \\ admeire@gmail.com \\ Ana Cristina de Albuquerque \\ Doutora, Universidade Estadual de Londrina, Londrina, PR, Brasil; \\ albuanati@uel.br
}

\begin{abstract}
Resumo: Colecionismo bibliográfico é uma prática que envolve a reunião de materiais bibliográficos fundamentada em questões subjetivas. Os estudos, nessa área, buscam compreender as razões nas quais se pautam as motivações que permeiam a patologia, o documental e o valor financeiro relacionados ao ato de colecionar; subentende-se, dessa maneira, a necessidade de estudos interdisciplinares. Nesse contexto, questiona-se: qual é o estado da arte dos estudos relacionados ao colecionismo bibliográfico no contexto da Ciência da Informação no Brasil? Assim, o cerne desta pesquisa consiste em apresentar uma compreensão teórico-documental dos estudos relacionados ao colecionismo bibliográfico, e também abordar a terminologia utilizada, os principais estudos desenvolvidos na área e as perspectivas para desenvolvimento de novos estudos a respeito do tema. O método é bibliográfico e bibliométrico-documental. Evidenciou-se que os estudos se iniciaram a partir do ano 2000, no entanto, foi só a partir de 2007 que se recuperaram estudos no Encontro Nacional de Pesquisa em Ciência da Informação. Os estudos recuperados estabelecem diálogos entre a Ciência da Informação, Museologia, Memória Social, Psicologia e Comunicação Social. Destaca-se a baixa incidência de estudos voltados ao colecionismo bibliográfico e a necessidade de abordagens que contemplem também o colecionismo bibliográfico em meio digital.
\end{abstract}

Palavras-chave: Colecionismo bibliográfico. Acervos especiais. Patrimônio bibliográfico. Bibliofilia. Bibliomania.

\section{Introdução}

A Ciência da Informação é uma área que busca seus pilares conceituais em diversos campos. Desse modo, os estudos que trazem temas com abordagens interdisciplinares necessitam direcionar e delimitar os nortes teóricos e conceituais escolhidos através de bases amplas e que deem conta dos objetos estudados. Para tanto, acredita-se na necessidade de retomar o conceito de 
documento de Suzanne Briet (1970). Segundo a autora, o documento consiste em "[...] todo indício concreto ou simbólico, conservado ou registrado, com a finalidade de representar, reconstituir ou provar um fenômeno físico ou intelectual." (BRIET, 1970, p. 60). Essa característica quase testemunhal atribuída aos documentos permite estabelecer uma ligação entre os estudos a respeito de colecionismo bibliográfico e a Ciência da Informação, quando se parte da materialidade do indício e se observam as estruturas organizacionais e representativas que existem em torno do ato do colecionismo bibliográfico. Esses estudos permeiam a perspectiva particular, mas remetem também ao ambiente institucional.

Isso posto, o presente artigo tem o objetivo de analisar como o colecionismo bibliográfico é discutido na área da Ciência da Informação, haja vista que as motivações para abordar o colecionismo bibliográfico vêm de perspectivas de estudos desenvolvidas por pesquisadores da área tanto por sua constituição quanto pela institucionalização dos itens e sua organização e representação. Partindo-se desse objetivo, percebeu-se, mesmo com as discussões de possibilidade de debates que contribuam para a Ciência da Informação, a baixa incidência de estudos que abordam o colecionismo bibliográfico como cerne das discussões. Portanto, o presente artigo se justifica por contribuir com a análise e sistematização das discussões teóricas em torno das nuances do colecionismo, além de ilustrar o cenário atual, retratando as pesquisas existentes sobre a temática na área.

Apresenta-se um quadro teórico, a partir da revisão bibliográfica, que discute o colecionismo ao longo do tempo, evidenciando essa prática desde os primórdios e os termos utilizados para se referir à reunião particular de livros, a saber: colecionismo bibliográfico, bibliofilia e bibliomania. O método utilizado foi o bibliométrico-documental, que permitiu o levantamento dos estudos e apresenta a tabulação de artigos, teses e dissertações cujo assunto é colecionismo e o colecionismo bibliográfico.

Em relação aos resultados, compreende-se a presença de estudos em Programas de Pós-Graduação de Memória Social e Comunicação Social como importantes para a apreensão do tema colecionismo e consequentemente para 
diálogos com e dentro da Ciência da Informação, além de ser observada a necessidade de a área se voltar com maior atenção a esse tema, que é, por vezes, diluído em estudos transversais.

\section{Colecionismo: panorama histórico}

A necessidade de reunir objetos relaciona-se diretamente com dois objetivos principais: manter e preservar. $\mathrm{O}$ manter corresponde diretamente à questão da manutenção do passado, pois as características sociais podem ser passadas para as próximas gerações, também, por meio dos objetos. O preservar remete à guarda, que subentende a garantia da continuidade de elementos associados aos aspectos histórico-socioculturais (SUANO, 1986).

Desse modo, os objetos coletados desempenham dupla ação: simbólica e funcional. Essa dualidade, apresentada por Baudrillard (2004), remete à retirada da função original de determinado item, isto é: o elemento perde a sua funcionalidade e passa a exercer o papel simbólico, desempenhando uma ação de alegoria por meio de sua existência.

Cabe pontuar que existe uma diferença significativa entre acumular e colecionar. O primeiro relaciona-se ao apego excessivo a todo tipo de objeto, sem uma preocupação com ordem e representatividade e sem senso de continuidade. Colecionar está associado à busca, por meio de objetos, da representação de si próprio; à busca por manter continuidade social, por preservar para a posteridade e por estabelecer o autoconhecimento por meio de objetos. Colecionar difere de acumular também por causa da definição de coleção, que, nesta pesquisa, busca o olhar institucional e se fundamenta na definição de coleção de Pomian (2000):

[...] qualquer conjunto de objectos naturais ou artificiais, mantidos temporária ou definitivamente fora do circuito das actividades econômicas, sujeitos a uma protecção especial num local fechado preparado para esse fim, e expostos ao olhar do público. (POMIAN, 2000 p. 53).

O comentário de Pomian (2000) subentende a questão do desligamento com a funcionalidade original, pois o objeto passa a carregar sentidos além dos 
usuais. Isso ocorre por meio da exposição, que vem acompanhada de uma encenação que visa transmitir os valores implícitos e explícitos do objeto. Sendo assim, a leitura institucional e o olhar do outro reforçam a função simbólica, que remete à compreensão alegórica e cumpre o papel de preservar informações para as gerações posteriores.

A definição para coleção, voltada para a instância particular, se centra na questão comprobatória. Assim sendo, uma coleção pode ser compreendida como "[...] um testemunho de algo, seja um fato ou um período; não possui valor usual, apenas valor simbólico e de troca, carrega a subjetividade de quem a constituiu, representa algo e é reflexo do indivíduo [...]" (SANTOS, 2015, p. 27 apud BAUDRILLARD,2004).

Convém ponderar que "a ideia de coleção não é uma invenção moderna" (CRIPPA, 2005, p. 31), pois isso permite refletir em torno do objetivo e o sentido histórico das coleções; afinal, a retirada de um objeto do seu uso subentende que o objeto possui um passado. Além disso, quando se define e se entende uma coleção, torna-se possível a construção de recortes em instância temporal e social dos objetos coletados (CRIPPA, 2005, p. 31).

A partir dos estudos da cultura material, é possível uma compreensão das razões para colecionar. A cultura material pode ser entendida como uma parte física do meio ambiente, aqui compreendido como o todo, de que o homem se apropria socialmente e em cuja existência intervém, modelando, dando forma a seus elementos e manipulando-os em favor de um objetivo (MENESES, 1983).

Assim, "Para analisar, portanto, a cultura material, é preciso situá-la como suporte material, físico, imediatamente concreto, da produção e reprodução da vida social.” (MENESES, 1983, p. 112). Portanto, ao longo do tempo, os motivos para o colecionismo estiveram atrelados aos aspectos sociais e culturais vigentes com a característica de reter a natureza a seu favor. Suano (1986) categorizou as razões, que são: “[...] preservação do prestígio social, valor mágico, lealdade de grupo, curiosidade e pesquisa." (SUANO, 1986, p. 12).

Ao olhar para a história da humanidade, percebe-se que o colecionismo esteve sempre presente. Os primeiros indícios remetem à questão da 
sobrevivência, pois a identificação de um novo instrumento era essencial para o avanço e desenvolvimento humano. Para Marshall (2005),

O colecionismo do caçador-coletador pré-histórico implica uma grande proficiência sensorial, certa argúcia taxonômica, enorme sentido do espaço e uma relação intensa entre desejo e necessidade, mediados pelo conhecimento. (MARSHALL, 2005, p. 14).

As coleções no período medieval apresentavam um viés teocêntrico, bem como representavam vitórias em batalhas travadas entre reinos e ilustravam as riquezas dos colecionadores, que usualmente eram os reis e/ou os governantes (BLOM, 2003), pois os detentores do poder tinham uma postura e uma gestão conformes à crença de serem eleitos por Deus. Nesse contexto, as coleções caracterizavam todo o simbolismo em torno do poder que esses homens representavam em diálogo com o sagrado e o viés dos objetos representava o conhecimento fundamentado no sagrado.

Como já pontuado em estudos anteriores de Sundström e Bizello (2016), há três períodos que foram marcantes para o colecionismo: Renascentista, Iluminista e Contemporâneo (RENAULT; ARAÚJO, 2015).

O período Renascentista foi marcante, pois foi um momento de ruptura, em que o homem estava no centro das discussões. Durante o Renascimento, o advento das navegações tornou viável o contato dos europeus com elementos de terras distantes da Europa para compor coleções, além das coleções que continham espécimes naturais, como uma forma de buscar o conhecimento desprendido, em certa medida, dos alicerces religiosos (BLOM, 2003).

É no Iluminismo que o interesse em estruturar o conhecimento por meio do método e criticidade se consolidou, e tais características refletiram na formação das coleções. Dessa maneira, as coleções formadas nesse período traziam elementos que vinham para comprovar e validar determinados conhecimentos. Os elementos comprobatórios também serviam como base para elaboração de novos conhecimentos (BLOM, 2003).

$\mathrm{Na}$ contemporaneidade, muitos objetos são produzidos para ser colecionados, como, por exemplo, as séries de livros com edições especiais para colecionadores; as coleções de brinquedos; as sagas de livros e elementos em 
torno desse universo, dentre muitos outros. Torna-se incontável o número de elementos que podem ser colecionados.

Desse modo, segundo Renault e Araújo (2015), esse período se caracteriza pela "serialização dos objetos" fundamentado pelo consumismo. Assim, acrescenta-se, também, que quanto mais a memória se perde, mais ela necessita de lugares (NORA, 1990). Diante disso, essa quantidade de itens pode refletir a necessidade de repositórios da memória, e o medo do esquecimento se torna, também, razão para coletar (SUNDSTRÖM; BIZELLO, 2016).

Ainda na perspectiva do colecionismo contemporâneo, cabe mencionar os armazenamentos digitais, pois estes proporcionam facilidade de acesso e reprodução, mas, em contrapartida, geram ainda certa insegurança quanto à preservação a longo prazo. Uma das consequências desse sentimento é a infinidade de cópias do mesmo documento em mídias diferentes, o que configura um novo espaço para reflexões à luz do colecionismo bibliográfico.

O novo cenário faz aflorar alguns questionamentos: como fica a questão da exposição e da experiência das coleções no ambiente digital? Essa dinâmica altera a materialidade do livro e de outros objetos da coleção e promove novas discussões a esse respeito. Crippa (2005) trata dessa desmaterialização das coleções proporcionada pela tecnologia e propõe uma reflexão instigante acerca do acesso a coleções digitais. Para Crippa (2005), toda essa complexidade "[...] impõe discutir o novo papel da própria essência das antigas coleções em seu suporte digital, espaço sem espaço, onde a materialidade se torna ausente." (CRIPPA, 2005, p. 46).

As discussões em torno do colecionismo se imbricam na relevância com que o colecionismo se mostra em diferentes processos e momentos históricos, assumindo de forma complexa algumas funções que ensejam seu próprio desenvolvimento cultural e organizacional. Nessa perspectiva se configura o colecionismo bibliográfico.

\section{Colecionismo bibliográfico: bibliofilia ou bibliomania?}

"Colecionismo" é um neologismo que nomeia o ato de formar uma coleção. A etimologia da palavra subentende uma patologia, pois o uso do sufixo "-ismo", 
no contexto brasileiro, esteve atrelado à Medicina, e nesse campo, o sufixo designava intoxicação por algum agente, por exemplo, "alcoolismo" e “iodismo" (HOUAISS, 2001 apud GIANASTACIO, 2008, p. 7). Nessa perspectiva, o colecionismo, etimologicamente, é uma intoxicação por coleta. Gianastacio ainda complementa que a ascensão da ciência permitiu o uso do sufixo também em outros contextos: "[...] movimentos sociais, políticos, ideológicos, religiosos e personativo [...]" (HOUAISS, 2001 apud GIANASTACIO, 2008, p. 7).

Quando se busca o significado de "colecionismo" por meio da análise das falas dos colecionadores, a prática se torna quase um sinônimo de hobby, pois as leituras de Rubens Borba de Moraes (2005) e Mindlin (1997) dão essa impressão. Para os autores, que também são colecionadores, o colecionismo consiste em uma atividade voltada à salvaguarda de materiais bibliográficos de importância histórico-cultural, na qual o processo de busca é repleto de prazer e satisfação pessoal (SUNDSTRÖM; BIZELLO, 2016).

Os estudos que abordam o colecionismo também utilizam o termo "bibliofilia" para especificar o ato de coletar voltado aos livros. O significado da palavra está atrelado ao amor dos colecionadores bibliófilos pelos livros; desse modo, "bibliofilia" conota uma relação de amizade entre o colecionador e os livros (REIFSCHNEIDER, 2011).

Quando Reifscheider (2011) recupera a etimologia da palavra, ele escreve que ela foi utilizada pela primeira vez no século XIV, por Ricardo Bury, no Philobiblion. $\mathrm{O}$ autor ainda menciona outros termos relacionados a formações de coleções, como: iconofilia, colecionismo de imagem; filatelia, colecionismo de selos postais, e cartofilia, colecionismo de cartões postais (REIFSCHNEIDER, 2011, p. 71).

Desse modo, o radical "-filia" remete ao ato de coletar algo e o radical que se antepõe a "-filia" para formar a palavra indica o item coletado. Outro aspecto salientado pelo autor, que se faz relevante para esta discussão, é o seguinte: "Avaliar o simbolismo que esses termos carregam é compreender, também, as reações dos próprios colecionadores em relação ao seu fazer." (REIFSCHNEIDER, 2011, p. 71-72). Portanto, refletir sobre a terminologia 
adotada, seja pelo indivíduo colecionador, seja pela abordagem seguida em dada pesquisa sobre colecionismo, contribui para entender o modo como o indivíduo lida com o ato ou qual corrente teórica foi a base da pesquisa.

Outro radical também importante é "-mania", que, de acordo com os estudos de Reifschneider (2011), está associado a um distúrbio comportamental ou, até mesmo, à insanidade. Sendo assim, "bibliomania" difere de "bibliofilia" porque a primeira expressa algo negativo e a segunda, bibliofilia, conota sentimentos positivos como, por exemplo, a amizade e o amor (REIFSCHNEIDER, 2011).

Ao refletir sobre a terminologia, muitos autores buscam os fundamentos para construir seu aporte teórico nas razões para coletar e, assim, por meio de entrevistas com colecionadores e instituições recebedoras de doações, mapeiam os motivos para coletar e, no último caso, quando ocorre a institucionalização, para receber. No estudo de Reifschneider (2011), o autor aponta três aspectos que devem ser identificados no indivíduo para ele ser classificado como bibliófilo: "[...] a atração (compulsão) pela coisa, a busca por conhecimento (pesquisa) e o interesse especulativo (investimento).” (REIFSCHNEIDER, 2011, p. 76).

Outro estudo, já recapitulado em nossas outras pesquisas, é de Ruth Formanek (2005), no capítulo de livro intitulado Why they collect: collectors reveal their motivations, em que a autora analisa as respostas de vários colecionadores para tentar entender as razões de coletar. Ela elenca cinco razões, a saber: “ [...] (1) para si mesmo ; (2) para os outros; (3) como preservação, restauração, história e um senso de continuidade; (4) como investimento financeiro e (5) como vício [...]" (FORMANEK, 2005, p. 327, tradução nossa).

Outra autora, que também aponta as razões para coletar, é Susan Pearce (2005). Ela parte do ponto de vista institucional, pois analisa as coleções que adentram em um museu e, a partir disso, as classifica em três tipos diferentes: "coleções como lembranças, objetos de fetiche e como sistemática" (PEARCE, 2005, p. 194, tradução nossa).

Com "collections as souvenirs", que pode ser traduzido como coleções de memórias, ou coleções de recordações, a autora explica que o item sozinho 
pode carregar o passado (PEARCE, 2005). Para o colecionamento fetichista, a autora indica a presença de itens repetidos, como, por exemplo, o colecionador de latas de cervejas, maços de cigarros, e outros. Por fim, a autora apresenta o que compreende como coleções sistemáticas, que consistem em coleções que possuam objetivos e viés muito bem esclarecidos (SANTOS, 2015).

As pesquisas identificadas permitem visualizar três grandes vieses de abordagem para o colecionismo bibliográfico, que são: o patológico, o da documentação e o financeiro. O patológico volta-se para o preenchimento de necessidades subjetivas por meio dos objetos e também para distúrbios mentais caracterizados pela dificuldade em desapegar-se de itens aleatórios. Formanek (2005) retoma os estudos de Freud (1963) para fundamentar esse tipo de colecionismo e pontua que o colecionismo, nesse norte teórico, é entendido como uma sublimação do conflito anal. "Esse conflito tem origem na infância, e os autores acreditam que as fezes, por ser o primeiro produto fabricado pelo ser humano, desenvolvem no indivíduo certa superestimação por coisas simbólicas" (FORMANEK, 2005, p. 216 apud SANTOS, 2015, p. 31).

Cabe citar como exemplo o filme $O$ cheiro do ralo, do diretor Heitor Dhaila, produzido no ano de 2007. O personagem central é interpretado por Selton Mello e na trama ele compra coisas usadas, de pessoas com problemas financeiros; alguns itens ele revende e outros, ele guarda para sua coleção particular. Dessa maneira, como não conheceu o pai, reúne objetos com o objetivo de criar um perfil para o pai desconhecido (SANTOS, 2015).

Vai ser a perna do meu pai, é, eu já tenho um olho, eu sei que com o tempo eu vou montar meu pai, meu pai Frankenstein. Ele só saiu com minha mãe uma vez, eu nem sei seu nome e nunca me viu, nunca soube o quanto o amei, ele foi, eu fiquei. Ele é mais triste que eu porque talvez ele não tenha ninguém e eu tenho ele. Meu pai Frankenstein. (O CHEIRO. DO RALO.., 2007, doc. não paginado).

Também nesse viés patológico, Reifschneider (2011) comenta a questão do fetichismo, que empresta sentido mágico aos objetos coletados e pode ser um modo de evidenciar que algum conflito sexual vem sendo reprimido. A quinta razão apontada por Formanek (2005), "as addiction", traduzido como vício, 
também subentende um distúrbio psicológico, pois nesta categoria a autora insere as pessoas que compram itens por serem viciadas em compras.

O viés documental pode ser identificado em vários estudos. Em Formanek (2005) associamos a ele a noção de "Coletar como preservação, restauração, história e um senso de continuidade" (FORMANEK, 2005, p. 333, tradução nossa), que abarca o ato de coletar como um modo de preservar e transmitir o aprendizado por meio dos itens. Os estudos na Biblioteconomia buscam constantemente, nessa vertente, a fundamentação teórica para respaldar a presença de coleções de obras raras e especiais em ambientes institucionais, para entender as nuanças em torno da memória coletiva e social, além de um modo de trabalhar a complexidade entre o público e o privado de coleções institucionalizadas.

Com o senso de continuidade, portanto, adquire-se um caráter de repositório, seja memorialístico ou informacional. As leituras de Benjamin (1987, 2006) abordam o caráter alegórico, pois o autor trata das relações que as coleções desempenham com fatos anteriormente vividos. Outro autor que compreende a coleção como um repositório é Murguia-Marañon (2007). Para ele, o livro na coleção pode ser compreendido além da sua possibilidade informacional e adquire o sentido de semióforo.

O viés comercial traz estudos voltados para o setor livreiro, porque são poucos os colecionadores que veem no colecionismo um potencial para o acúmulo de capital, devido a presença de outros sentimentos que se destacam em alguns colecionadores. Formanek (2005) também ressalta isso em sua pesquisa, na quarta categoria identificada por ela "como investimento financeiro" (as financial investment) (FORMANEK, 2005, p. 333), referindo-se a um investimento financeiro. Na Ciência da Informação, os estudos dentro dessa perspectiva são voltados para o controle da segurança, pois há registro de furtos de obras raras com valor financeiro elevado.

Cabe citar o exemplo da Biblioteca Pedro Calmon, da Universidade Federal do Rio de Janeiro, que teve 303 obras raras furtadas no ano de 2016, o que caracterizou o furto como o maior já registrado até então no Brasil, de 
acordo com a matéria do $\mathrm{O}$ Estadão. Entre as obras furtadas, a matéria disponível no jornal O Estadão destaca:

[...] os 16 volumes da primeira edição dos Sermões de padre Antônio Vieira (1679) e quase toda a coleção Brasiliana do acervo, composta por livros de viajantes europeus que registraram flora, fauna e costumes do País dos séculos 17 ao 19. Sumiram preciosidades como Expédition dans les parties centrales de l'Amérique du Sud (1850-1859), do naturalista inglês Francis de Castelnau, com centenas de litografias pintadas a mão; os quatro volumes de um livro do etnógrafo alemão Thomas Koch-Grümberg, pioneiro da fotografia antropológica, com 141 fotos de indígenas da região dos rios Japurá e Negro, na Amazônia, retratados entre 1903 e 1905. O principal alvo foram obras com gravuras, que costumam ser cortadas a navalha e vendidas separadas. (BRANDALISE; RIBEIRO, 2017, doc. não paginado).

O responsável pelos furtos foi identificado, era um ex-estudante do curso de Biblioteconomia. A matéria informa que ele foi preso, porque encontraram em seu apartamento algumas das obras desaparecidas (BRANDALISE; RIBEIRO, 2017). Ele também já havia sido preso por outros furtos de obras raras. A matéria também informa que a vida do responsável pelos furtos será retratada em um filme, o que mobilizou protestos contrários à elaboração do projeto (BRANDALISE; RIBEIRO, 2017).

Além da questão do furto, existe também o valor de troca, pois o valor dos objetos é atribuído em âmbito social. No caso, o valor comercial das obras raras está atrelado a uma atribuição simbólica, que permeia o valor cultural; assim, convém destacar que "A cultura assim se dedica à tarefa mais modesta de criar equivalência de valor dentro de diversas esferas específicas de mercadoria. "(KOPYTOFF, 2008, p. 98).

De acordo com Crippa (2005), o valor pode também estar associado à impossibilidade de acesso ou a restrições dele, afinal, quando reconhecido o valor de troca simbólica, o acesso é monitorado ou impossibilitado.

Desse modo, compreende-se que o termo utilizado é "colecionismo bibliográfico" quando os estudos abordam a coleção por um viés documental, principalmente, em processo de institucionalização. Encontram-se os termos "bibliofilia" e "bibliomania" associados aos estudos que tratam da formação de coleção como patologia e, por vez, os termos "colecionismo", "bibliofilia" e 
"bibliomania" são tratados como sinônimos com mais frequência no setor comercial. Ressalta-se também que quando os estudos partem do ponto de vista do colecionador, o termo utilizado é "bibliofilia", aplicado também em sentido documental.

\section{Perspectivas de estudos na área}

Foram escolhidas bases de dados para mapear o andamento de estudos sobre colecionismo e colecionismo bibliográfico na Ciência da Informação no Brasil. Os termos escolhidos foram "bibliomania", "bibliofilia", "colecionismo bibliográfico" e "colecionismo". As bases de dados foram: o Repositório digital dos trabalhos apresentados nos Encontros Nacionais de Pesquisa em Ciência da Informação (BENANCIB) - que traz todos os trabalhos apresentados nos Grupos de Trabalho (GTs) do Encontro Nacional de Pesquisa em Ciência da Informação (ENANCIB); a Base de Dados de Periódicos em Ciência da Informação (BRAPCI) - que indexa os principais periódicos da área da Ciência da Informação; o Portal de Periódicos da Coordenação de Aperfeiçoamento de Pessoal de Nível Superior (CAPES) e a Biblioteca Digital Brasileira de Teses e Dissertações (BDTD).

Os textos recuperados foram analisados por meio da leitura dos trabalhos de forma integral, em que se buscou destacar o foco das abordagens e também nas palavras-chave utilizadas. As duplicatas foram descartadas e a ordem escolhida para a tabulação foi cronológica. São três tabelas com os trabalhos recuperados e analisados. A primeira (Quadro 1) corresponde aos estudos que abordam o colecionismo de outros objetos, mas que são relevantes para a compreensão desse fenômeno, pois, mesmo não cedendo ênfase ao colecionismo bibliográfico, apresentam aspectos que viabilizam os diálogos interdisciplinares do tema e buscam, em alguns casos, a construção de revisão bibliográfica.

Cabe destacar também o critério de exclusão adotado. Foram descartados os estudos que divergiam do foco da análise: os estudos nos quais se analisa o livro como objeto de obra de arte, os trabalhos de conclusão de curso de graduação e os trabalhos dos programas de pós-graduação da área de Administração sobre o colecionismo relacionado ao consumismo. 
Quadro 1 - Textos referentes ao assunto "colecionismo"

\begin{tabular}{|c|c|c|}
\hline Autores & Título & Ano \\
\hline $\begin{array}{l}\text { PEDROCHI, Mara Angelica; } \\
\text { MURGUIA-MARAÑON, } \\
\text { Eduardo Ismael }\end{array}$ & $\begin{array}{l}\text { O devir de uma coleção: a institucionalização do } \\
\text { Museu Eduardo André Matarazzo de armas, } \\
\text { veículos e máquinas }\end{array}$ & 2007 \\
\hline $\begin{array}{l}\text { RIBEIRO, } \\
\text { Beatriz; COSTA, } \\
\text { Castro }\end{array}$ & $\begin{array}{l}\text { Toy story 2: a trajetória identitária-informacional } \\
\text { de um objeto de coleção }\end{array}$ & 2008 \\
\hline $\begin{array}{l}\text { ESPÍRITO SANTO, Silvia } \\
\text { Maria do }\end{array}$ & $\begin{array}{l}\text { Alguns elementos do problema entre colecionismo } \\
\text { e contexto cultural }\end{array}$ & 2010 \\
\hline COSTA, Thaina Castro & $\begin{array}{l}\text { Informação, memória e objetos: uma análise sobre } \\
\text { coleções na narrativa fílmica } O \text { cheiro do ralo }\end{array}$ & 2010 \\
\hline COSTA, Thaina Castro & $\begin{array}{l}\text { O passado presentificado na coleção de cartas da } \\
\text { Sra. Madeleine Wallace ( } O \text { fabuloso destino de } \\
\text { Amélie Poulain) }\end{array}$ & 2011 \\
\hline $\begin{array}{l}\text { ESPÍRITO SANTO, Silvia } \\
\text { Maria do }\end{array}$ & $\begin{array}{l}\text { A contribuição do colecionismo para historiografia } \\
\text { do Museu Histórico do antigo "Oeste Paulista" }\end{array}$ & 2011 \\
\hline
\end{tabular}

Fonte: Elaborado pelas autoras.

Pedrochi e Murguia-Marañon (2007) buscam a compreensão da coleção do Museu de armas Eduardo André Matarazzo e descrevem o processo de institucionalização, trazendo alguns questionamentos que permeiam a relação entre público e privado. As palavras-chave são "coleção", "colecionismo", "Museu Eduardo André Matarazzo" e "processo de institucionalização".

O estudo de Ribeiro e Costa (2008) utiliza o filme Toy story 2 como objeto de análise para identificar a atribuição de valor e informação aos objetos de coleção. As palavras-chave são "coleção", "informação", "objetos de coleção" e "Toy story 2". 
Por sua vez, Costa (2010) busca, por meio do filme $O$ cheiro do ralo (de 2007), entender a reconfiguração dos objetos inseridos em coleção, que se dá por meio do colecionador. As palavras-chave são "informação", "memória" e "O cheiro do ralo". Em novo trabalho, no ano seguinte, Costa (2011) continua seu processo de análise por meio dos filmes. Nesse artigo, o objeto de análise é o filme $O$ fabuloso destino de Amélie Poulain. A autora busca compreender as relações com a memória e entender o processo de informação nas coleções. Palavras-chave: "memória", "informação", "análise fílmica" e "objetos de coleção".

O trabalho de Espirito Santo (2010) busca o significado da palavra colecionismo a partir da palavra americana collection. A autora traz uma abordagem da compreensão da coleção por meio do museu (ESPIRITO SANTO, 2010). Palavras-chave: "coleção de museu", "museu" e "História".

O próximo quadro (Quadro 2) demostra os estudos mais voltados para o colecionismo bibliográfico. Ressalta-se que alguns estudos podem ter ficado de fora devido à escolha das palavras-chave.

Quadro 2 - Textos referentes aos assuntos “colecionismo bibliográfico", "bibliofilia” e "bibliomania"

\begin{tabular}{|c|c|c|}
\hline Autores & Título & Ano \\
\hline $\begin{array}{l}\text { MURGUIA-MARAÑON, } \\
\text { Eduardo Ismael }\end{array}$ & $\begin{array}{l}\text { O colecionismo bibliográfico: uma reflexão sobre } \\
\text { o livro para além da informação }\end{array}$ & 2007 \\
\hline $\begin{array}{l}\text { GAUZ, Valeria; PINHEIRO, } \\
\text { Lena Vania Ribeiro }\end{array}$ & $\begin{array}{l}\text { Fluxo da informação entre colecionadores, } \\
\text { escribas e cientistas árabes na pré- } \\
\text { institucionalização da ciência, séculos IV ao XV }\end{array}$ & 2010 \\
\hline $\begin{array}{l}\text { BATISTA, Denise Maria da } \\
\text { Silva; RANGEL, } \\
\text { Ferreira }\end{array}$ & $\begin{array}{l}\text { Museus Castro Maya: de coleção privada a museu } \\
\text { público }\end{array}$ & 2012 \\
\hline $\begin{array}{l}\text { MELO, Kelly Castelo Branco } \\
\text { da Silva; RIBEIRO, Leila }\end{array}$ & $\begin{array}{l}\text { Bibliófilos e bibliodetetives: personagens de } \\
\text { informação e memória }\end{array}$ & 2013 \\
\hline
\end{tabular}




\begin{tabular}{|c|c|c|}
\hline Beatriz & & \\
\hline $\begin{array}{lr}\text { SANTOS, } & \text { Admeire } \\
\text { Silva; BIZELLO, } & \text { Maria } \\
\text { Leandra } & \end{array}$ & $\begin{array}{l}\text { Influência do colecionismo na representação da } \\
\text { memória social: relações práticas e teóricas e suas } \\
\text { contribuições para o desenvolvimento da } \\
\text { sociedade }\end{array}$ & 2013 \\
\hline $\begin{array}{l}\text { PEDRÃO, Gabriela Bazan; } \\
\text { MURGUIA-MARAÑON, } \\
\text { Eduardo Ismael. }\end{array}$ & $\begin{array}{l}\text { Formação das bibliotecas: uma abordagem desde a } \\
\text { perspectiva do colecionismo }\end{array}$ & 2013 \\
\hline $\begin{array}{l}\text { MELO, Kelly Castelo Branco } \\
\text { da Silva; RIBEIRO, Leila } \\
\text { Beatriz }\end{array}$ & $\begin{array}{l}\text { Nas fontes, a memória: a bibliofilia nas aventuras } \\
\text { de Clifford Janeway }\end{array}$ & 2014 \\
\hline $\begin{array}{lr}\text { SANTOS, } & \text { Admeire } \\
\text { Silva; BIZELLO, } & \text { Maria } \\
\text { Leandra } & \end{array}$ & $\begin{array}{l}\text { O livro como um lugar de memória: o caso da } \\
\text { coleção Amidicis Tocantis }\end{array}$ & 2014 \\
\hline $\begin{array}{l}\text { RENAULT, } \quad \text { Leonardo } \\
\text { Vasconcelos; } \quad \text { ARAÚJO, } \\
\text { Carlos Alberto de Ávila. }\end{array}$ & O ato colecionador: perspectivas contemporâneas & 2015 \\
\hline $\begin{array}{l}\text { RENAULT, } \quad \text { Leonardo } \\
\text { Vasconcelos; }\end{array}$ & $\begin{array}{l}\text { O ato colecionador: uma visão a partir das } \\
\text { disciplinas de Arquivologia, Biblioteconomia e } \\
\text { Museologia }\end{array}$ & 2015 \\
\hline $\begin{array}{l}\text { SUNDSTRÖM, Admeire da } \\
\text { Silva Santos; BIZELLO, } \\
\text { Maria Leandra }\end{array}$ & $\begin{array}{l}\text { Coleção de livros e a memória nas entrelinhas: } \\
\text { análise da coleção Amidicis Tocantins }\end{array}$ & 2016 \\
\hline $\begin{array}{l}\text { ARAÚJO, Diná Marques } \\
\text { Pereira; REIS, Alcenir Soares } \\
\text { dos }\end{array}$ & $\begin{array}{l}\text { Bibliotecas, bibliofilia e bibliografia: alguns } \\
\text { apontamentos }\end{array}$ & 2016 \\
\hline RIBEIRO, Ana Elisa & $\begin{array}{l}\text { O bibliógrafo digital: questões sobre a } \\
\text { materialidade do livro no século XXI }\end{array}$ & 2017 \\
\hline
\end{tabular}

Fonte: Elaborado pelas autoras. 
O primeiro estudo da tabela acima é o de Murguia-Marañon (2007). O texto foi apresentado no VII ENANCIB e serve de base, ainda hoje, para a Ciência da Informação e todos os estudos em torno dessa temática. O autor desenvolve a possibilidade de se olhar para o livro além do aspecto informacional, no contexto da Ciência da Informação brasileira (MURGUIAMARAÑON, 2007). Palavras-chave: "coleções", "colecionismo bibliográfico" e "livros".

Neste sentido, Gauz e Pinheiro (2010) explanam a importância dos colecionadores e escribas árabes para transmissão da cultura. As palavras-chave utilizadas são: "História da informação científica"; "Ciência medieval"; “colecionadores da Idade Média"; "árabes na Ciência" e "História da Ciência". Cabe destacar um trecho:

\begin{abstract}
Os colecionadores, até os dias atuais, ocupam lugar de destaque na preservação de coleções valiosas para os estudos históricos e científicos de áreas do conhecimento as mais diversas. Sua função sofreu mudanças nesses quase dois milênios que se passaram: de preservadores, reprodutores e disseminadores da informação, hoje se estabelecem como guardiões de um saber que, se ainda se mantém, é graças à paixão aos livros, em uma época em que esses não apresentam mais a mesma importância para o mundo científico. (GAUZ; PINHEIRO, 2010, p. 16).
\end{abstract}

No trabalho de Batista e Rangel (2012), a coleção de Castro Maya é apresentada e contextualizada com a História do Rio de Janeiro. O colecionador era um coletor de obras de arte e os livros eram um dos itens de suas coleções. Palavras-chave: "institucionalização de coleções", "Museus Castro Maya História" e "colecionismo".

Em Melo e Ribeiro (2013), é analisado o discurso de colecionadores a partir de textos de ficção e de depoimentos de colecionadores reais, buscando, assim, uma correlação entre o livro, a literatura e a memória. Palavras-chave: "bibliofilia"; "memória"; "romance policial".

Santos e Bizello (2013) apresentam os conceitos de coleção e lugar de memória. Palavras-chave: "colecionismo"; "memória social”; “institucionalização de acervos".

Pedrão e Murguia-Marañon (2013) exploram a relação do indivíduo colecionador com a biblioteca no momento de composição do acervo. Assim, os 
autores também contribuem para discussões em torno do colecionismo, coleções e colecionadores. Palavras-chave: "colecionismo", "coleções", "bibliotecas pessoais" e "livros".

Em Santos e Bizello (2013), são apresentados dados de entrevistas e a possibilidade de entender uma coleção de livros como um lugar de memória por meio dos aspectos destacados pelos responsáveis pelo cuidado e pela manutenção da coleção. Palavras-chave: "colecionismo"; "lugar de memória"; "Amidicis Tocantins".

Os trabalhos de Renault e Araújo (2015) e Renault (2016) buscam demonstrar o que os autores denominam de "ato colecionador", que envolve a união das três áreas: Biblioteconomia, Arquivologia e Museologia. Pelo compreendido, o ato colecionador seria uma adesão entre o desenvolvimento de coleção, o conceito institucional e o colecionismo, reunião em instância privada. Palavras-chave: "Biblioteconomia"; "Arquivologia"; "Museologia"; “colecionismo". O segundo artigo de Renault e Araújo (2015) dá continuidade à proposta de compreender as três áreas por meio do colecionismo, mas, desta vez, buscam o respaldo em Pomian (1984) para definir o conceito de coleção.

Com Sundström e Bizello (2016), é apresentado o resultado final dos estudos que analisam a coleção Amidicis Tocantins e sua relação com a instituição. Desse modo, as autoras, tendo em vista o contexto em que estava a coleção, entenderam que o caminho viável para o diálogo com a memória coletiva era o conceito de memória literária. Palavras-chave: "coleção"; "memória"; "colecionismo"; "Coleção Amidicis Diogo Tocantins"; "memória literária".

O estudo de Araújo e Reis (2016) não se volta ao colecionismo como central, mas aborda a relevância do colecionismo para as bibliografias de livros raros. Palavras-chave: "Ciência da Informação"; "bibliografia"; "bibliografia material"; "livros raros".

Com Ribeiro (2017), têm-se as primeiras reflexões em torno da leitura, da aquisição e da formação de coleção a partir dos dispositivos digitais. A autora traça questionamentos que envolvem a relação do escritor com o livro, do leitor 
com o livro e da questão da materialidade do livro (RIBEIRO, 2017). Palavraschave: "livro impresso"; "livro digital"; "bibliofilia"; "bibliografia".

\begin{tabular}{|c|c|c|}
\hline Autor (a) & Título & Ano \\
\hline ARANTES, Carolina Pinto & $\begin{array}{l}\text { Coleções: um estudo dos processos criativos e } \\
\text { comunicacionais }\end{array}$ & $\begin{array}{l}\text { Dissertação } \\
\text { (2010) }\end{array}$ \\
\hline COSTA, Thainá Castro & $\begin{array}{l}\text { Colecionando o invisível: o reordenamento de } \\
\text { mundo a partir de objetos de descarte }\end{array}$ & $\begin{array}{l}\text { Dissertação } \\
(2012)\end{array}$ \\
\hline SANTOS, Admeire da Silva. & $\begin{array}{l}\text { A influência do colecionismo na representação } \\
\text { da memória social: análise da coleção Amidicis } \\
\text { Tocantins }\end{array}$ & $\begin{array}{l}\text { Dissertação } \\
(2015)\end{array}$ \\
\hline $\begin{array}{l}\text { SOUZA, Maria de } \\
\text { Fátima Medeiros de }\end{array}$ & $\begin{array}{l}\text { O estudo da coleção de livros da sociedade dos } \\
\text { cem bibliófilos do Brasil da Biblioteca Central } \\
\text { da Universidade de Brasília }\end{array}$ & $\begin{array}{l}\text { Dissertação } \\
(2016)\end{array}$ \\
\hline $\begin{array}{l}\text { REIFSCHNEIDER, Oto Dias } \\
\text { Becker. }\end{array}$ & A bibliofilia no Brasil & Tese (2011) \\
\hline $\begin{array}{l}\text { RENAULT, Leonardo } \\
\text { Vasconcelos. }\end{array}$ & $\mathrm{O}$ ato colecionador & Tese (2015) \\
\hline $\begin{array}{l}\text { MELO, Kelly Castelo Branco } \\
\text { da Silva }\end{array}$ & $\begin{array}{l}\text { Bibliófilos e bibliodetetives: personagens de } \\
\text { patrimônio e memória }\end{array}$ & $\begin{array}{l}\text { Dissertação } \\
(2015)\end{array}$ \\
\hline
\end{tabular}

Fonte: Elaborado pelas autoras.

Arantes (2010) fundamenta sua dissertação sobre o processo de formação de coleção em Blom (2003) e traz outros teóricos para construir o embasamento teórico sobre o processo de formação de coleção. A autora associa $\mathrm{o}$ ato de colecionar com o processo comunicativo e entende o colecionismo como uma possibilidade de comunicação (ARANTES, 2010). A dissertação é da área da Comunicação Social, desenvolvida no Programa de Pós-Graduação em Comunicação e Semiótica, mas traz argumentação sobre o processo de reunião de objetos. Palavras-chave: "comunicação"; "processos de criação"; "memória"; "coleção"; "consumo".

Santos (2015) buscou entender os caminhos que uma coleção institucionalizada pode percorrer para ser entendida como representante da 
memória coletiva. O conceito de memória literária foi trabalhado à luz desse objetivo. Palavras-chave: "coleção"; "memória"; "colecionismo"; "Coleção Amidicis Diogo Tocantins"; "memória literária".

Em sua dissertação, na área da Ciência da Informação, do Programa de Pós-Graduação da Universidade de Brasília, Souza (2016) analisa a coleção "Sociedade dos Cem Bibliófilos do Brasil (1943-1969) do Setor de Obras Raras da Biblioteca Central da Universidade de Brasília - BCE/ UnB”. A autora estuda a procedência da coleção, a história dos itens da coleção e depois a exposição e consulta do acervo (SOUZA, 2016). Palavras-chave: "Sociedade dos Cem Bibliófilos do Brasil"; "Biblioteca Central da UnB"; "livro de arte"; "livro de bibliófilo"; "obras raras"; "colecionismo bibliográfico".

A tese de Reifschneider (2011), na área da Ciência da Informação, também apresentada no Programa de Pós-Graduação da Universidade de Brasília e já citada neste trabalho, enfatiza os aspectos históricos, sociológicos e comunicacionais da bibliofilia no Brasil. $O$ autor destaca os principais colecionadores do Brasil, além de discutir os “[...] aspectos simbólicos, estéticos e econômicos, do fascínio da obra rara à importância de bibliotecas particulares." (REIFSCHNEIDER, 2011, p. 04). O estudo não apresenta palavras-chave e no repositório institucional a única palavra-chave encontrada foi "bibliomania".

Renault (2015) apresentou artigos, no decorrer do desenvolvimento de sua tese, e, neste trabalho final, pontua as relações entre as áreas as quais acredita construírem diálogos entre si, a saber Arquivologia, Biblioteconomia e Museologia, atravessadas pela discussão sobre colecionismo. A tese foi defendida no Programa de Pós-Graduação em Ciência da Informação da Universidade Federal de Minas Gerais. As palavras-chave são: "colecionismo"; "Arquivologia"; "Biblioteconomia"; "Museologia e Epistemologia".

A dissertação de Melo (2015) foi apresentada no Programa de Memória Social, da Unirio, e aborda o colecionismo por meio de um romance policial, no qual o personagem central, o detetive bibliófilo Clifford Janeway, constrói diálogos em torno do colecionismo e de sua relação com os livros. Melo (2015) apresenta essa relação em diálogo com os autores que abordam o colecionismo 
dentro da área. Dessa maneira, o estudo apresenta a relação entre os objetos colecionados e a memória na perspectiva patrimonial. Palavras-chave: "bibliofilia"; "coleção"; "livro"; "memória"; "romance policial”.

\section{Considerações finais}

A partir das discussões levantadas neste trabalho, foram identificadas três correntes em estudos do colecionismo bibliográfico no Brasil: patológico, documental e financeiro. A primeira delas traz a compreensão e estudos à luz do ponto de vista do colecionador; portanto, quando tais estudos mapeiam entrevistas, eles identificam as razões para colecionar, sempre pautadas em questões subjetivas, mas que agregam, também, memória social, coletiva e individual, a partir de um ponto de vista de extensão de si.

A perspectiva documental abarca a importância dos colecionadores e suas coleções para a cultural nacional. Assim, o termo "colecionismo" corresponde à prática da coleta de elementos relacionada à importância documental, apresentando um passado de interesse comum. O ponto de vista financeiro está associado ao valor de troca simbólica, no qual os elementos de coleção estão associados ao valor cultural de que eles são investidos e também à impossibilidade do acesso.

As palavras-chave evidenciam que, ao longo do tempo, os estudos foram desenvolvendo-se a partir da mediação da informação, passando a integrar estudos dentro da Informação e memória e da Museologia. Os termos escolhidos também especificam o tipo documental, bem como a coleção analisada. O processo de institucionalização é carregado de carga simbólica, pois, no contexto privado, a coleção é tratada, por vez, como excentricidade, hobby, paixão e lazer, ao passo que, quando institucionalizada, a coleção é compreendida por meio de um viés documental, e passa a se considerar que ela representa importantes traços da cultural geral.

Ao término das respectivas análises, compreendeu-se que os estudos na Ciência da Informação buscam o conceito de colecionismo ou colecionismo bibliográfico quando se deparam com problemáticas em torno de recebimento de coleções. Assim, o uso do conceito se torna uma possibilidade de abordagem 
no momento de encontrar soluções para possíveis problemáticas de interpretação de acervos doados às instituições públicas. Tais termos, então, correspondem à aproximação da reunião privada de coleções e a instituição pública.

Outra importante conclusão é a preocupação com a desmaterialização de coleções físicas e migração desse ato para a instância tecnológica; o ato de migrar para coleta digital, ou também a presença de coleções em museus em instância digital, até o momento, não interferiam nas definições de coleção, colecionismo e colecionadores. Ao que indica a literatura brasileira, a desmaterialização dos objetos colecionáveis só interferiu, até o momento, nos processos de construção da memória, pois há a necessidade de repensar os modos interação da sociedade em ambiente digital.

\section{Referências}

ARANTES, Carolina Pinto. Coleções: um estudo dos processos criativos e comunicacionais. 2010. Dissertação (Mestrado em Comunicação) - Pontifícia Universidade Católica de São Paulo, São Paulo, 2010.

ARAÚJO, Diná Marques Pereira; REIS, Alcenir Soares dos. Bibliotecas, Bibliofilia e Bibliografia: alguns apontamentos. InCID, Ribeirão Preto, v. 7, p. 183-201, 2016.

BATISTA, Denise Maria da Silva. Museus Castro Maya: de coleção privada a museu público. 2012. Dissertação (Mestrado em Museologia e Patrimônio) Programa de Pós-Graduação em Museologia e Patrimônio, Universidade Federal do Estado do Rio de Janeiro, Rio de Janeiro, 2012.

BATISTA, Denise Maria da Silva; RANGEL, Marcio Ferreira. Museus Castro Maya: de coleção privada a museu público. In: Museologia, Patrimônio, Interculturalidade: museus inclusivos, desenvolvimento e diálogo intercultural. Anais....Rio de Janeiro : Museu de Astronomia e Ciências Afins: Universidade Federal do Estado do Rio de Janeiro, Programa de Pós-Graduação em Museologia e Patrimônio, 2013. p. 142-151.

BAUDRILLARD, Jean. A moral dos objetos: função-signo e lógica de classe. In: MOLES, Abranham Semiologia dos objetos. Petrópolis: Vozes, 1972. cap. 2, p. 42-87.

BAUDRILLARD, Jean. O sistema dos objetos. São Paulo: Perspectiva, 2004. 
BENJAMIN, Walter. Desempacotando minha biblioteca: um discurso sobre o colecionador. In: Rua de mão Única: Obras escolhidas. V. II. Brasileiense: São Paulo, 1987.

BENJAMIN, Walter. O colecionador. In: BENJAMIN, Walter. Passagens. Belo Horizonte: UFMG, 2006. Cap. 2. p.237-245

BLOM, Philipp. Ter e manter: uma história intima de colecionadores e coleções. Rio de Janeiro: Record, 2003.

BRANDALISE, Vitor Hugo; RIBEIRO, Bruno. UFRJ sofre o maior furto de livros raros do Brasil. O Estadão, São Paulo, 30 abr. 2017. Disponível em: https://brasil.estadao.com.br/noticias/rio-de-janeiro, ufrj-sofre-o-maior-furto-delivros-raros-do-brasil,70001757824. Acesso em: 25 jun. 2018.

BRIET, Suzanne. O que é documentação. Niterói: Universidade Federal Fluminense, 1970.

COSTA, T. C. O passado presentificado na coleção de cartas da Sra Madeleine Wallace (o fabuloso destino de amelie poulain). In: ENCONTRO NACIONAL DE PESQUISA EM CIÊNCIA DA INFORMAÇÃO, 17., 2011 Brasília. Anais [...]. Brasília: ANCIB, 2011 p. 3449-3454.

COSTA, Thaina Castro. Informação, memória e objetos: uma análise sobre coleções na narrativa fílmica O Cheiro do Ralo. In: ENCONTRO NACIONAL DE PESQUISA EM CIÊNCIA DA INFORMAÇÃO, 17., 2010 Rio de Janeiro. Anais [...]. Rio de Janeiro: ANCIB, 2010.

COSTA, Thainá Castro. Colecionando o invisível: o reordenamento de mundo a partir de objetos de descarte. 2012. Dissertação (Mestrado em Memória Social) - Programa de Pós-Graduação em Memória Social, Universidade Federal do Estado do Rio de Janeiro, Rio de Janeiro, 2012.

CRIPPA, Giulia. Entre paixão e necessidade: a arte de colecionar, os espaços da memória e do conhecimento na história. In: FURNIVAL, Ariadne Chloë; COSTA, Luzia Sigoli Fernanes. Informação e conhecimento: aproximando áreas do saber. São Carlos: EdUFSCar, 2005. p. 29-48.

ESPÍRITO SANTO, Silvia Maria do. Alguns elementos do problema entre colecionismo e contex to cultural. In: ENCONTRO NACIONAL DE PESQUISA EM CIÊNCIA DA INFORMAÇÃO, 11., 2010, Rio de Janeiro. Anais [...]. Rio de Janeiro: ANCIB, 2010. p. 1-19.

FORMANEK, Ruth. Why they collect: collectors reveal their motivations, In: PEARCE, Susan (Organizadora). Interpreting objects and collections. New York: Routledge, 2005. 343 p.

GAUZ, Valéria; PINHEIRO, Lena Vânia Ribeiro. Fluxo da Informação entre colecionadores, escribas e cientistas árabes na pré-institucionalização da 
Ciência, séculos IV ao XV. In: ENCONTRO NACIONAL DE PESQUISA EM CIÊNCIA DA INFORMAÇÃO, 11., 2010, Rio de Janeiro. Anais [...]. Rio de Janeiro: ANCIB, 2010. p. 1-19.

GIANASTACIO, Vanderlei. O sufixo - ISMO na história das gramáticas da língua portuguesa e sua produtividade a partir do dicionário de língua Portuguesa Antônio Houaiss. In: SIMPÓSIO MUNDIAL DE ESTUDOS DE LÍNGUA PORTUGUESA, 1., 2008, São Paulo. Anais [...]. São Paulo: USP 2008. p. 1-18.

Houaiss, Antônio. Dicionário da língua portuguesa Houaiss. Rio de Janeiro: Objetiva, 2007.

KOPYTOFF, Igor. A biografia cultural das coisas: a mercantilização como um processo. In: APPADURA, Arjun A vida social das coisas: as mercadorias sob uma perspectiva cultural. Niterói: EdUFF, 2008. cap. 2, p. 89-121.-

MARSHALL, Francisco. Epistemologias históricas do colecionismo. Episteme, Porto Alegre, n. 20, p. 13-23, 2005.

MELO, Kelly Castelo Branco da Silva.; RIBEIRO, Leila Beatriz. Bibliófilos e bibliodetetives: personagens de informação e memória. In: ENCONTRO NACIONAL DE PESQUISA EM CIÊNCIA DA INFORMAÇÃO, 14., 2013, Florianópolis. Anais [...]. Florianópolis: UFSC, 2013. p. 1-7.

MELO, Kelly Castelo Branco da Silva.; RIBEIRO, Leila Beatriz. Nas fontes, a memória: a bibliofilia nas aventuras de clifford janeway. In: ENCONTRO NACIONAL DE PESQUISA EM CIÊNCIA DA INFORMAÇÃO, 15., 2014, Belo Horizonte. Anais [...]. Belo Horizonte: ANCIB, 2014. p. 5123-5129.

MELO, Kelly Castelo Branco da Silva. Bibliófilos e Bibliodetetives: personagens de patrimônio e memória. 2015. Dissertação (Mestrado em Memória Social) - Programa de Pós-Graduação em Memória Social, Universidade Federal do Estado do Rio de Janeiro, Rio de Janeiro, 2015.

MENESES, U. T. B. de. A cultura material no estudo das sociedades antigas. Revista de História da USP, São Paulo, n. 15, p. 103-117, 1983.

MINDLIN, José. Uma vida entre livros: Reencontros com o tempo. São Paulo: Editora da Universidade de São Paulo: Companhia das letras, 1997. 231p.

MORAES, Rubens Borba de. O bibliófilo aprendiz: Prosa de um velho colecionador para ser lida por quem gosta de livros, mas pode também servir para de pequeno guia aos que desejam formar uma coleção de obras raras, antigas ou modernas. Rio de janeiro: Casa da palavra, 2005. 207p.

MURGUIA-MARAÑON, Eduardo Ismael. O colecionismo bibliográfico: uma reflexão sobre o livro para além da informação. In: ENCONTRO NACIONAL 
DE PESQUISA EM CIÊNCIA DA INFORMAÇÃO, 8., 2007, Salvador. Anais [...]. Salvador: UFBA, 2007. p. 1-15.

NORA, Pierre. Entre memória e história: o problema dos lugares. Revista do programa de Pós-graduados e do departamento de história da PUC-USP. São Paulo: [S.I], 1981.

O CHEIRO do ralo. Direção: Heitor Dhaila. Brasil: Branca Filmes 2007. DVD (112 min), son., color.

PEARCE, Susan (Organizadora). Interpreting objects and collections. New York: Routledge, 2005. 343 p.

PEDRÃO, Gabriela Bazan.; MURGUIA-MARAÑON, Eduardo Ismael. Formação das bibliotecas: uma abordagem desde a perspectiva do colecionismo. Em Questão, Porto Alegre, v. 19, n. 2, p. 396-415, 2013.

PEDROCHI, Mara Angélica; MURGUIA-MARAÑON, Eduardo Ismael. O devir de uma coleção: a institucionalização do Museu "Eduardo André Matarazzo" de armas, veículos e máquinas. In: ENCONTRO NACIONAL DE PESQUISA EM CIÊNCIA DA INFORMAÇÃO, 8., 2007, Salvador. Anais [...]. Salvador: UFBA, 2007. p. 1-15.

POMIAN, Krzystof. História cultural, história dos semióforos. RIOUX, J-P; SIRINELLI, J-F (Orgs.). In: Para uma história cultural. Lisboa: Estampa, 1998.

POMIAN, Krzystof. Coleção. In: GIL, Fernando (org.). Memória-História. Porto: Imprensa Nacional, 1984. p. 51-86.

POMIAN, Krzystof. Memória. In: Enciclopédia Einaudi. Lisboa: Imprensa Nacional, 2000. p. 507-516. (Sistemática, v. 42).

REIFSCHNEIDER, Oto Dias Becker. A bibliofilia no Brasil. 2011. Tese (Doutorado em Ciência da Informação) - Programa de Pós-graduação em Ciência da Informação, Universidade de Brasília, Brasília, 2011.

RENAULT, Leonardo Vasconcelos.; ARAÚJO, Carlos Alberto Ávila. O ato colecionador: perspectivas contemporâneas. ACB, São José, v. 20, n. 2, p. 185 199, 2015.

RENAULT, Leonardo Vasconcelos. O ato colecionador. 2015. Tese (Doutorado em Ciência da Informação) - Programa de Pós-Graduação da Escola de Ciência da Informação, Universidade Federal de Minas Gerais, Belo Horizonte, 2015. 


\section{RENAULT, Leonardo Vasconcelos.. O ato colecionador. Bibliotecas}

Universitárias: pesquisas, experiências e perspectivas, v. 3, n. 2, p. 6768, 2016. Disponível em:

<http://hdl.handle.net/20.500.11959/brapci/17045>. Acesso em: 01 abr. 2020.

RIBEIRO, Ana Elisa. O bibliógrafo digital: questões sobre a materialidade do livro no século XXI. Perspectivas em Ciência da Informação, Belo Horizonte, v. 22, p. 120-130, 2017.

RIBEIRO, Leila; COSTA, Thainá. Toy Story 2: a trajetória identitáriainformacional de um objeto de Coleção. In: ENCONTRO NACIONAL DE PESQUISA EM CIÊNCIA DA INFORMAÇÃO, 9., 2008, São Paulo. Anais [...]. São Paulo: USP, 2008. p. 1-13.

SANTOS, Admeire da Silva Santos; BIZELLO, Maria Leandra. A influência do colecionismo na representação da memória social: relações práticas e teóricas e suas contribuições para o desenvolvimento da sociedade. In: ENCONTRO NACIONAL DE PESQUISA EM CIÊNCIA DA INFORMAÇÃO, 14., 2013, Florianópolis Anais [...]. Florianópolis UFSC, 2013. p. 1-6.

SANTOS, Admeire da Silva. A influência do colecionismo na representação da memória social: análise da coleção Amidicis Tocantins. 2015. Dissertação (Mestrado em Ciência da Informação) - Faculdade de Filosofia e Ciências, Universidade Estadual Paulista Júlio de Mesquita Filho, Marília, 2015.

SOUZA, Maria de Fátima Medeiros de. O estudo da coleção de livros da sociedade dos cem bibliófilos do Brasil da Biblioteca Central da Universidade de Brasília. 2016. Dissertação (Mestrado em Ciência da Informação) - Faculdade de Ciência da Informação, Universidade de Brasília, Brasília, 2016.

SUANO, Marlene. O que é museu. São Paulo: Brasiliense, 1986. (Coleção Primeiros Passos, 182).

SUNDSTRÖM, Admeire da Silva Santos.; BIZELLO, Maria Leandra. Coleção de livros e a memória nas entrelinhas: análise da coleção Amidicis

Tocantins. In: ENCONTRO NACIONAL DE PESQUISA EM CIÊNCIA DA INFORMAÇÃO, 17., 2016, Salvador Anais [...]. Salvador UFBA, 2016, p. 116.

SUNDSTRÖM, Admeire Santos; BIZELLO, Maria Leandra. Coleções de Livros na Perspectiva da Memória Literária: o caso da Coleção Amidicis Tocantins. In: SEMINÁRIO EM CIÊNCIA DA INFORMAÇÃO, 6., 2016, Londrina Anais [...]. Londrina UEL 2016. p. 872-884. 


\title{
Bibliographic collecting: historical context, terminology and research perspectives in Information Science
}

\begin{abstract}
Bibliographic collecting is a practice that involves the gathering of bibliographic materials based on subjective issues. Research in that area seeks to understand the reasons underlying the pathologic, the documentary and the economic motivations related to the act of collecting; this implies the need for interdisciplinary studies. In this context, the question is: what is the state of the art of studies related to bibliographic collecting in the context of Information Science in Brazil? Thus, the core of this study is to present a theoretical and documentary understanding of studies related to bibliographic collecting. The paper also aims to address the terminology used, the main studies developed in the area and the prospects for carrying out new research in the subject. The method is bibliographic and bibliometric-documentary. We found that papers concerning bibliographic collecting were mainly published from the year 2000 on; however, it was only from 2007 on that we retrieved research documented in the proceedings of editions of the Encontro Nacional de Pesquisa em Ciência da Informação. The studies retrieved draw connections between Information Science, Museology, Social Memory, Psychology and Social Communication. We highlight the low incidence of studies focused on bibliographic collecting and the need for approaches that also contemplate bibliographic collecting in digital media.
\end{abstract}

Keywords: Bibliographic Collecting. Special collections. Bibliographic estate. Bibliophilia. Bibliomania. 